\title{
NOTE ON TRANSLITERATION AND USAGE
}

Throughout the text, I have employed a modified form of the Library of Congress's Russian transliteration system. When proper names have a generally accepted English variant, I have used this in the body of the text (Scriabin rather than Skriabin, Rachmaninoff rather than Rakhmaninov, Medtner rather than Metner). In citations of Russian sources, the names appear in transliterated form in the notes (Skriabin, Rakhmaninov, Metner). Prior to February 1918, Russia adhered to the Julian calendar, which, in the early twentieth century, was thirteen days behind the Gregorian. Unless otherwise noted, dates in Russian sources are given in the Julian style (Old Style), while European sources are given in the Gregorian style (New Style). In correspondence between Russia and Europe, both dates are generally given (as was common in original sources), separated by slashes. After February 1918, all dates given are in the Gregorian style. Unless otherwise indicated, all musical analyses and translations are my own. 
This page intentionally left blank 